\title{
Movement disorder profile and treatment outcomes in a one-year study of patients with schizophrenia
}

This article was published in the following Dove Press journal:

Neuropsychiatric Disease and Treatment

13 June 2013

Number of times this article has been viewed

Lei Chen

Haya Ascher-Svanum

Anthony Lawson

Virginia L Stauffer

Allen Nyhuis

Virginia Haynes

Kory Schuh

Bruce J Kinon

Eli Lilly and Company,

Indianapolis, IN, USA
Correspondence: Lei Chen

Eli Lilly and Company, Lilly Corporate

Center, Drop Code 1730,

Indianapolis IN 46285, USA

$\mathrm{Tel}+\mathrm{I} 3176550916$

Email lei_chen_Ic@lilly.com
Background: This study identified subgroups of patients with schizophrenia who differed on their movement disorder profile and compared their treatment outcomes.

Methods: Data from a randomized, open-label, one-year study of patients with schizophrenia who were treated with antipsychotics in usual clinical care settings were analyzed $(n=640)$. Five measures of movement disorder were incorporated into a single Movement Disorder Index (MDI). Subgroups that differed in their movement disorder profile over the one-year study period were compared on clinical and functional outcomes.

Results: Three subgroups were identified: a worsening of MDI in $15 \%$ of patients, an improvement in 33\%, and no change in 53\%. Compared with the other two subgroups, the MDIworsened subgroup had poorer symptom improvement measured by the Positive and Negative Syndrome Scale (PANSS) total score (mean changes of $-11.0,-18.4$, and -16.8 for the patients who had a worsening of MDI, no change, and an improvement, respectively), poorer symptom improvement on the PANSS positive and anxiety/depression subscale scores, worsening on the 36-Item Short Form Health Survey (SF-36) physical component summary score, and a higher rate of hospitalization $(P<0.05)$.

Conclusion: Patients with schizophrenia who experience worsening of their MDI score appear to have poorer clinical and functional outcomes, suggesting that such worsening may be a marker of poorer prognosis.

Keywords: schizophrenia, treatment outcome, movement disorder

\section{Introduction}

Movement disorders have long been associated with antipsychotic treatment. ${ }^{1}$ Antagonism of dopamine D2 receptors can resolve psychosis but may induce extrapyramidal symptoms (EPS), which are some of the most troubling adverse events during treatment with antipsychotics. These symptoms include acute dystonia, akathisia, parkinsonism, and tardive dyskinesia. The incidence rate for tardive dyskinesia, the most disabling and potentially irreversible symptom of EPS, is approximately $24 \%$ after seven years of exposure to first-generation antipsychotics. ${ }^{2} \mathrm{~A}$ study of the longterm effects of first-generation antipsychotics estimated the risk of persistent tardive dyskinesia to be $57 \%$ after 15 years of exposure. ${ }^{3}$ The evidence suggests that treatmentemergent tardive dyskinesia rates might be even greater in older patients. ${ }^{4}$

A benefit of the newer second-generation antipsychotics is a reduced risk, compared with first-generation antipsychotics, of inducing acute EPS at recommended dose ranges..$^{5}$ A review of 11 long-term studies lasting at least one year and reporting the incidence of tardive dyskinesia showed that second-generation antipsychotics 
have a reduced risk of tardive dyskinesia compared with first-generation antipsychotics. ${ }^{6}$ However, using data from the Clinical Antipsychotic Trials of Intervention Effectiveness study, Lieberman et $\mathrm{al}^{7}$ found no statistically significant difference in EPS rates between perphenazine, a first-generation antipsychotic, and second-generation antipsychotics (although patients with tardive dyskinesia were excluded from the perphenazine arm). However, in a secondary analysis of this study, Miller et $\mathrm{al}^{8}$ found a significant overall difference in use of antiparkinsonian medication and a difference in discontinuation rates due to Parkinsonism. This underscores the necessity to consider simultaneously several measures of EPS prevalence.

It appears that EPS remains a significant problem in the day-to-day management of patients with schizophrenia, even with second-generation antipsychotics. Development of EPS during treatment with second-generation antipsychotics depends on the specific medication, rapidity of dose escalation, target dose, and the patient's intrinsic vulnerability to EPS. ${ }^{1}$

Assessment of EPS often involves the simultaneous use of multiple measures, such as the Barnes Akathisia Rating Scale, 9,10 the Abnormal Involuntary Movement Scale (AIMS), ${ }^{11}$ and the Simpson-Angus Rating Scale, ${ }^{10,12}$ to capture different types of EPS and with each having a different threshold score. Interpretation of EPS data is complicated further by the use of different adjunctive antiparkinsonian medications that aim to ameliorate EPS. Therefore, in clinical and research settings, the presence of a movement disorder is typically assessed with different measures, each focusing on somewhat different aspects of the disorder. Results of patients' risk of movement disorder are reported for each measure individually, thus not providing a single overall composite parameter that can inform clinicians of the overall severity level of a patient's movement disorder, if present. A systematic and comprehensive method for assessing EPS and an index to capture several aspects of EPS, as assessed by various measures, while also incorporating the use of adjunctive antiparkinsonian medications, is needed. This could allow better assessment and more precise evaluation of the effects of antipsychotic medications on EPS and help identify subgroups of patients with a greater liability for EPS.

The objectives of this study were to develop a new index measure of movement disorder and evaluate its potential utility by identifying subgroups of patients with schizophrenia who differed on their movement disorder profile over a one-year period and compare their clinical and functional outcomes to determine if this movement disorder profile is related to treatment outcome. This study incorporated five measures of EPS into a single index, ie, the Movement Disorder Index (MDI). The hypothesis was that patients with worsening movement disorders, as measured by the MDI, would have poorer clinical and functional outcomes.

\section{Materials and methods Data source}

The data source for these analyses was Study F1D-USHGGD, a pragmatic schizophrenia trial that was designed to represent clinical care in the real-world context. This was a one-year, randomized, open-label study conducted in the United States to compare the cost-effectiveness of olanzapine as the initial treatment choice versus using olanzapine only after failure on one or two first-generation antipsychotics. It also compared the cost-effectiveness of olanzapine versus risperidone as initial therapy. ${ }^{13}$ All patients gave informed consent prior to study entry. The study was approved by the appropriate institutional review boards.

\section{Patients}

Patients were 18 years of age or older and diagnosed with schizophrenia, schizophreniform disorder, or schizoaffective disorder based on the Diagnostic and Statistical Manual of Mental Disorders, 4th Edition. ${ }^{14}$ Patients met criteria for exacerbation of psychotic symptoms or had recently experienced an adverse event attributable to current antipsychotic treatment. Patients with baseline data and at least one post-baseline assessment on EPS measures (Barnes Akathisia Rating Scale, AIMS, and Simpson-Angus Rating Scale) were included in characterizing the movement disorder subgroups $(n=640 ; 96 \%$ of 664 randomized patients in the study).

\section{Treatments}

Patients were randomized in a $1: 1: 1$ ratio to receive one of three treatments: olanzapine as initial therapy for a minimum of eight weeks, risperidone as initial therapy for a minimum of eight weeks, or treatment with a maximum of two oral first-generation antipsychotics for a minimum of eight weeks followed by a possible switch to olanzapine if clinically indicated. Patients began treatment with olanzapine at $10 \mathrm{mg}$ /day unless a lower starting dose was clinically indicated. Thereafter, patients received olanzapine 5-20 mg/day. Subsequent dosage adjustments were made as clinically indicated and according to recommendations 
in the package insert. Switching antipsychotic agents was allowed at the discretion of the treating physician. The protocol allowed adjunctive antiparkinsonian medications (benztropine mesylate, biperiden, amantadine, procycline, trihexyphenidyl, and propranolol) if EPS occurred or were pre-existing at study entry.

\section{Measures}

Assessments of symptoms, functioning, and EPS were made at baseline, at week 2, and at months 2, 5, 8, and 12 . Symptom severity was assessed using the Positive and Negative Syndrome Scale (PANSS) ${ }^{15}$ total score and subscale scores (positive, negative, impulsivity/hostility, disorganized thought, and anxiety/depression). ${ }^{16}$ Level of functioning was assessed with the 36-Item Short-Form Health Survey (SF-36) ${ }^{17}$ using the physical component summary (PCS) and mental component summary (MCS) scores. ${ }^{18}$

The MDI score was the sum of five EPS measures, each scored as present (yes $=1$ ) or absent (no $=0$ ). The five measures were the Simpson-Angus Rating Scale, ${ }^{12}$ Barnes Akathisia Rating Scale, ${ }^{9}$ AIMS, ${ }^{11}$ spontaneously reported movement disorder adverse events, and adjunctive antiparkinsonian medication use. Parkinsonism $=1$ if the Simpson-Angus total score was $>3 .{ }^{19}$ Using this scoring system, akathisia $=1$ if the Barnes global akathisia (item 4) score was $\geq 2 .{ }^{19}$ Dyskinesia $=1$ if there was a score $\geq 3$ on any one of the AIMS items (1-7) or a score $\geq 2$ on any two of these items. ${ }^{20}$ The above scales and thresholds have been extensively used in schizophrenia research. ${ }^{2,7,8,21-24}$ Antiparkinsonian medication use was coded as 1 if patients used a medication for at least 7 days in a row between the previous visit and the current visit; otherwise, it was coded as 0 . An EPS adverse event was coded as 1 if it was reported as having occurred anytime between the previous visit and the current visit; otherwise, it was coded as 0 . Thus, the MDI scores range from 0 to 5 , with higher scores indicating more severe movement disorders.

The MDI was used to identify subgroups of patients who differed in their movement disorder profile over the one-year study. These patient subgroups were then compared on treatment outcomes, including time to study dropout for any cause, symptom severity based on PANSS total and subscale scores, level of mental and physical functioning as measured by the SF-36, and hospitalization and emergency services utilization.

Health services utilization (hospitalization and emergency room visits) was extracted from patients' medical records by trained staff, using a resource utilization form developed for this study. Patients' prior adherence with antipsychotics was assessed via the medication possession ratio (MPR), ie, the proportion of days with any antipsychotic during the year prior to enrollment.

\section{Statistical analysis}

Patients were categorized into subgroups based on change in MDI from baseline to endpoint (MDI-worsened, MDI-no change, MDI-improved). Missing values on individual MDI component scores were handled by using last observation carried forward. Patient subgroups were then compared on baseline characteristics and treatment outcomes. Baseline characteristics were compared between subgroups using a $t$-test for continuous variables and a chi-square test for categorical variables. The log-rank test was used for time to study dropout. PANSS and standardized SF-36 scores were analyzed using the mixed model repeated measures method. The mixed model repeated measures model included the effects of MDI subgroup, investigator, visit, visit-by-MDI subgroup interaction, MPR, and baseline value of the outcome measure. Within-patient error terms were modeled using an unstructured covariance matrix. The Kenward-Roger method was used to estimate degrees of freedom for the denominator. A chi-square test was used to compare patient subgroups on hospitalization and emergency service use.

\section{Results}

For the overall population, the mean MDI score improved steadily over the one-year study period, from 0.97 at baseline to 0.67 at the one-year endpoint (Table 1). Figure 1 shows the distribution of MDI scores at each time point. The proportion of patients who had a score of 0 increased and the proportion of patients with a score of 4 or 5 (maximum score) decreased over time. There were no scores of 5 on the MDI after baseline.

Three subgroups of the MDI were identified: an increase in MDI over the one-year study was evident for $15 \%$ of

Table I Mean MDI scores for the overall population at each time point

\begin{tabular}{lllllll}
\hline Weeks & Week 0 & Week 2 & Week 8 & Week 20 & Week 32 & Week 48 \\
\hline Mean (SD) & $0.97(1.10)$ & $0.86(0.94)$ & $0.82(0.92)$ & $0.75(0.89)$ & $0.70(0.88)$ & $0.67(0.86)$ \\
\hline
\end{tabular}

Abbreviations: MDI, Movement Disorder Index; SD, standard deviation. 


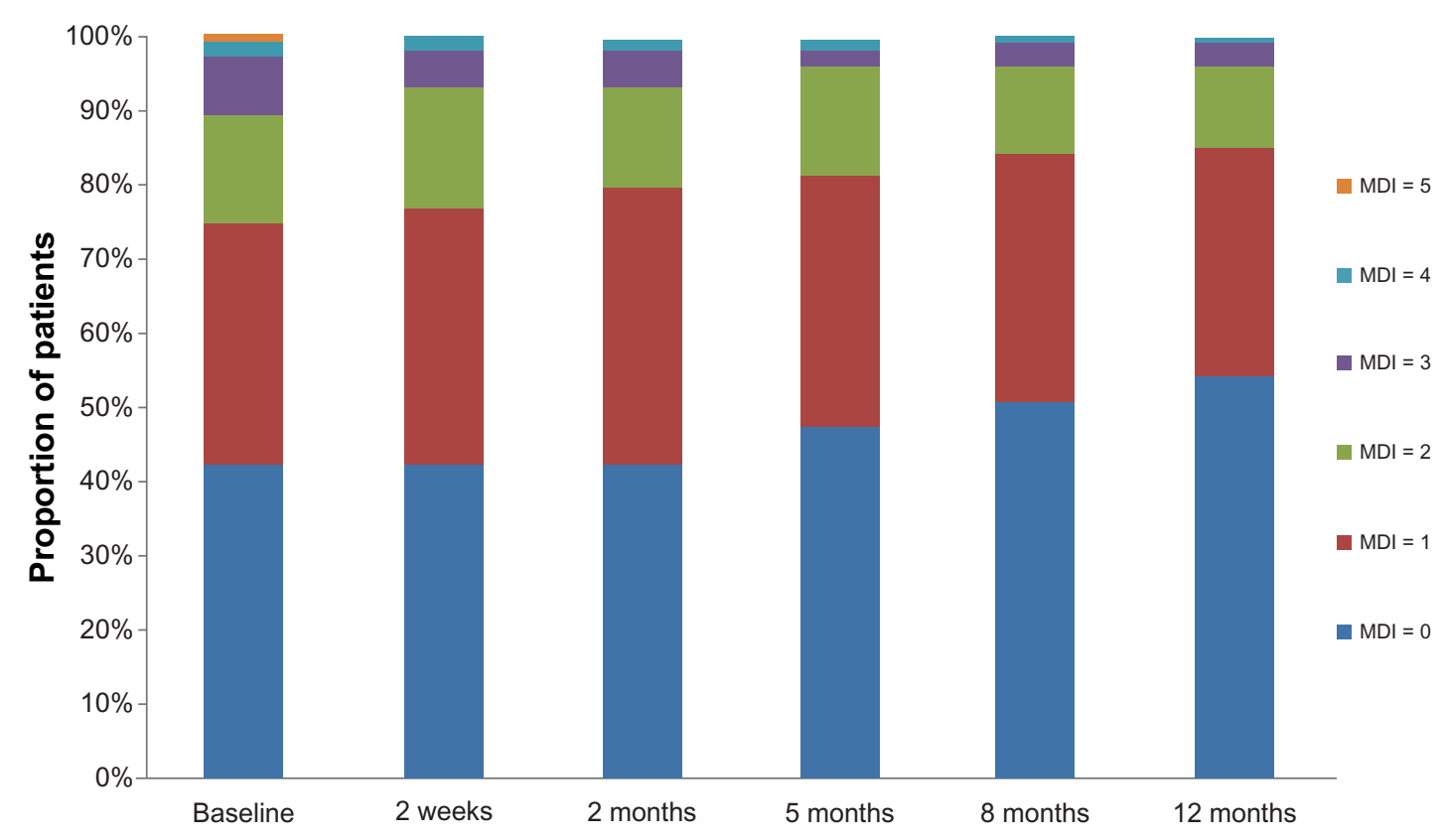

Figure I Distribution of Movement Disorder Index scores over the one-year study period.

Abbreviation: MDI, Movement Disorder Index.

the patients (MDI-worsened, $\mathrm{n}=95$ ); a decrease in MDI was observed for 33\% (MDI-improved, $\mathrm{n}=209$ ), and 53\% showed no change in MDI (MDI-no change; $n=336$ ). Patients in the MDI-worsened subgroup had a mean change of $1.2(78 \%$ had a 1 -point increase, $20 \%$ had a 2 -point increase, and $2 \%$ had a 3 -point increase). Patients in the MDI-improved subgroup had a mean change of $-1.5(65 \%$ had a 1 -point decrease, $22 \%$ had a 2 -point decrease, $12 \%$ had a 3-point decrease, and 1\% had a 4 -point decrease).

Baseline patient characteristics for each subgroup and the combined subgroups are shown in Table 2 . The results show that patients who were treated only with second-generation antipsychotics prior to study entry were less likely to be in the MDI-improved subgroup, African-American patients were less likely to be in the MDI-worsened subgroup, and schizoaffective patients were less likely to be in the MDIimproved subgroup. The MDI-improved subgroup also had a higher (worse) baseline MDI score, although the MDI-no change and MDI-worsened subgroups are comparable on baseline MDI score.

There was no statistically significant difference in time to treatment discontinuation or the study discontinuation rate between the three subgroups. The 25 th percentile time to discontinuation was 268 days, 253 days, and 365 days for the MDI-worsened, MDI-no change, and MDI-improved subgroups, respectively $(P=0.080)$. Of patients in the MDIworsened subgroup, 33\% discontinued treatment compared with $32 \%$ in the MDI-no change subgroup and $24 \%$ in the MDI-improved subgroup $(P=0.095)$.
The MDI-worsened subgroup was found to have significantly poorer clinical and functional outcomes on several measures compared with the other two subgroups $(P<0.05)$. Although all three subgroups had statistically significant within-group improvement on all PANSS items, the MDI-worsened subgroup had less symptom improvement compared with the other two subgroups on the PANSS total score and scores for the positive and anxiety/depression subscales (Table 3). The MDI-worsened subgroup also had less improvement than the MDI-no change subgroup on the negative and disorganized thought subscales. There were no significant differences between the three subgroups on change in the impulsive/hostility subscale score.

There were statistically significant differences between the MDI-worsened subgroup and the other two subgroups on most of the SF-36 scales and summary scores (Table 4). There were no significant differences between the MDIimproved and MDI-no change subgroups on the SF-36 summary and component scale scores.

Notably, the MDI-worsened subgroup had statistically significant within-group decreases (worsening) from baseline on the SF-36 PCS, driven by worsening in physical functioning, role-physical, and bodily pain subscale scores (Table 4), while within-group changes on MCS were not statistically significant. In contrast, the MDI-improved and MDI-no change subgroups had statistically significant within-group increases (improvement) from baseline for the MCS and several subscales but no significant within-group change on the PCS. 
Table 2 Baseline patient characteristics by MDI subgroup

\begin{tabular}{|c|c|c|c|c|c|c|c|}
\hline & \multirow{2}{*}{$\begin{array}{l}\text { Total } \\
n=640\end{array}$} & \multicolumn{3}{|c|}{ MDI subgroup } & \multicolumn{3}{|l|}{$P$ value } \\
\hline & & $\begin{array}{l}\text { Worsened } \\
(n=95)\end{array}$ & $\begin{array}{l}\text { No change } \\
(n=336)\end{array}$ & $\begin{array}{l}\text { Improved } \\
(n=209)\end{array}$ & $\begin{array}{l}\text { Worsened vs } \\
\text { no change }\end{array}$ & $\begin{array}{l}\text { Worsened vs } \\
\text { improved }\end{array}$ & $\begin{array}{l}\text { No change vs } \\
\text { improved }\end{array}$ \\
\hline Age (years), mean (SD) & $42.9(12.1)$ & $43.2(12.0)$ & $42.8(12.6)$ & $42.9(11.2)$ & 0.739 & 0.835 & 0.860 \\
\hline Gender (\% male) & 63.4 & 64.2 & 64.6 & 61.2 & 1.000 & 0.702 & 0.465 \\
\hline Race/ethnicity & & & & & 0.114 & 0.023 & 0.513 \\
\hline Caucasian (\%) & 54.4 & 65.3 & 54.2 & 49.8 & & & \\
\hline African-American (\%) & 33.9 & 23.2 & 33.9 & 38.8 & & & \\
\hline Other (\%) & 11.7 & 11.6 & 11.9 & 11.5 & & & \\
\hline Primary psychiatry diagnosis & & & & & 0.498 & 0.287 & 0.010 \\
\hline Schizophrenia (\%) & 65.2 & 63.2 & 61.9 & 71.3 & & & \\
\hline Schizoaffective (\%) & 34.1 & 35.8 & 37.8 & 27.3 & & & \\
\hline Schizophreniform (\%) & 0.8 & I.I & 0.3 & 1.4 & & & \\
\hline Age at first psychiatric & $26.2(9.6)$ & $25.5(10.8)$ & $26.8(9.4)$ & $25.6(9.2)$ & 0.304 & 0.931 & 0.195 \\
\hline \multicolumn{8}{|l|}{ hospitalization, years } \\
\hline Inpatient setting at trial entry (\%) & 4.5 & 4.2 & 3.9 & 5.7 & 0.774 & 0.783 & 0.400 \\
\hline Antipsychotic treatment (past year) & & & & & 0.059 & $<0.001$ & $<0.001$ \\
\hline FGA only (\%) & 56.6 & 44.2 & 52.4 & 68.9 & & & \\
\hline SGA only (\%) & 14.1 & 15.8 & 19.9 & 3.8 & & & \\
\hline Both $(\%)$ & 19.4 & 27.4 & 15.5 & 22.0 & & & \\
\hline \multicolumn{8}{|c|}{ Comorbid psychiatric diagnosis (lifetime) } \\
\hline Mood disorder (\%) & 20.0 & 21.1 & 20.0 & 19.6 & 0.885 & 0.760 & 1.000 \\
\hline Anxiety (\%) & 5.5 & 7.4 & 5.4 & 4.8 & 0.460 & 0.421 & 0.844 \\
\hline Substance abuse (\%) & 44.3 & 47.4 & 46.4 & 39.4 & 0.908 & 0.211 & 0.131 \\
\hline PANSS total score, mean (SD) & $86.5(19.9)$ & $86.5(17.1)$ & $86.1(19.6)$ & $87.1(21.5)$ & 0.848 & 0.810 & 0.585 \\
\hline MCS, mean (SD) & $39.3(13.3)$ & $38.2(12.1)$ & 38.7 (13.7) & $40.7(13.1)$ & 0.757 & 0.124 & 0.097 \\
\hline PCS, mean (SD) & $45.7(10.4)$ & $44.0(9.2)$ & $46.1(10.9)$ & $45.9(10.0)$ & 0.102 & 0.133 & 0.828 \\
\hline MDI score, mean (median) & $0.97(\mathrm{I})$ & $0.47(0)$ & $0.49(0)$ & $1.99(2)$ & 0.892 & $<0.001$ & $<0.001$ \\
\hline MPR (past year), mean (SD)* & $0.52(0.43)$ & $0.44(0.43)$ & $0.47(0.43)$ & $0.62(0.42)$ & 0.615 & 0.002 & $<0.001$ \\
\hline
\end{tabular}

Note: $*_{\mathrm{n}}=570$.

Abbreviations: FGA, first-generation antipsychotics; MCS, mental component summary score; MDI, Movement Disorder Index; MPR, medication possession ratio; N/n, number; PANSS, Positive and Negative Syndrome Scale; PCS, physical component summary score; SD, standard deviation; SGA, second-generation antipsychotics.

Compared with the other subgroups, the MDI-worsened subgroup had a higher rate of hospitalization in the one-year follow-up period $(38 \%, 19 \%$, and $22 \%$ for the MDI-worsened, no change, and improved subgroups, respectively; $P<0.001$ ) and a trend toward a higher rate of emergency service use (38\%, 26\%, and $31 \%$, respectively; $P=0.061)$.

\section{Discussion}

This study incorporated five EPS measures into a single MDI score and used it to assess EPS in patients with schizophrenia and the link between EPS profile and treatment outcomes over a one-year period. Post hoc analysis found that patients who were treated with antipsychotics and experienced worsening

Table 3 Least square mean change scores and $95 \%$ confidence intervals for the PANSS

\begin{tabular}{|c|c|c|c|c|c|c|}
\hline & \multicolumn{3}{|c|}{ MDI subgroup } & \multicolumn{3}{|l|}{$P$ value } \\
\hline & $\begin{array}{l}\text { Worsened } \\
\mathrm{n}=86\end{array}$ & $\begin{array}{l}\text { No change } \\
n=296\end{array}$ & $\begin{array}{l}\text { Improved } \\
n=188\end{array}$ & $\begin{array}{l}\text { Worsened vs } \\
\text { no change }\end{array}$ & $\begin{array}{l}\text { Worsened vs } \\
\text { improved }\end{array}$ & $\begin{array}{l}\text { No change vs } \\
\text { improved }\end{array}$ \\
\hline Total score & -10.96 & -18.38 & -16.80 & 0.002 & 0.021 & 0.37 \\
\hline $95 \% \mathrm{Cl}$ & $-|5.2|,-6.7 \mid$ & $-20.99,-15.77$ & $-19.85,-13.76$ & & & \\
\hline Positive & -3.41 & -5.11 & -5.12 & 0.027 & 0.034 & 0.99 \\
\hline $95 \% \mathrm{Cl}$ & $-4.76,-2.05$ & $-5.95,-4.28$ & $-6.10,-4.14$ & & & \\
\hline Negative & -2.52 & -4.38 & -3.48 & 0.020 & 0.25 & 0.13 \\
\hline $95 \% \mathrm{Cl}$ & $-3.93,-1.12$ & $-5.24,-3.52$ & $-4.48,-2.47$ & & & \\
\hline Impulsivity/hostility & -1.24 & -1.69 & -1.57 & 0.24 & 0.41 & 0.68 \\
\hline $95 \% \mathrm{Cl}$ & $-1.93,-0.55$ & $-2.12,-1.27$ & $-2.07,-1.08$ & & & \\
\hline Disorganized thought & -2.63 & -4.78 & -3.93 & 0.001 & 0.056 & 0.075 \\
\hline $95 \% \mathrm{Cl}$ & $-3.78,-1.49$ & $-5.49,-4.08$ & $-4.75,-3.11$ & & & \\
\hline Anxiety/depression & -1.30 & -2.39 & -2.78 & 0.024 & 0.004 & 0.27 \\
\hline $95 \% \mathrm{Cl}$ & $-2.15,-0.45$ & $-2.91,-1.87$ & $-3.38,-2.17$ & & & \\
\hline
\end{tabular}

Note: The sample size in each MDI subgroup is slightly smaller than that in Table 2 due to the statistical model adjusting for MPR for which some patients had missing data. Abbreviations: $\mathrm{Cl}$, confidence interval; MDI, Movement Disorder Index; MPR, medication possession ratio; PANSS, Positive and Negative Syndrome Scale. 
Table 4 Least square mean change scores and $95 \%$ confidence intervals for the SF-36 scale

\begin{tabular}{|c|c|c|c|c|c|c|}
\hline & \multicolumn{3}{|c|}{ MDI subgroup } & \multicolumn{3}{|l|}{$P$ value } \\
\hline & $\begin{array}{l}\text { Worsened } \\
n=86\end{array}$ & $\begin{array}{l}\text { No change } \\
n=296\end{array}$ & $\begin{array}{l}\text { Improved } \\
n=\mid 88\end{array}$ & $\begin{array}{l}\text { Worsened vs } \\
\text { no change }\end{array}$ & $\begin{array}{l}\text { Worsened vs } \\
\text { improved }\end{array}$ & $\begin{array}{l}\text { No change vs } \\
\text { improved }\end{array}$ \\
\hline Physical functioning & -4.86 & 0.88 & 1.28 & $<0.00$ I & $<0.001$ & 0.73 \\
\hline $95 \% \mathrm{Cl}$ & $-7.70,-2.01$ & $-0.91,2.66$ & $-0.80,3.35$ & & & \\
\hline Role-physical & -3.43 & 1.67 & 1.03 & 0.004 & 0.017 & 0.61 \\
\hline $95 \% \mathrm{Cl}$ & $-6.57,-0.29$ & $-0.22,3.57$ & $-1.18,3.23$ & & & \\
\hline Bodily pain & -4.48 & 1.71 & 0.76 & $<0.001$ & 0.002 & 0.43 \\
\hline $95 \% \mathrm{Cl}$ & $-7.38,-1.58$ & $-0.08,3.49$ & $-1.32,2.84$ & & & \\
\hline General health & -2.13 & 0.37 & 1.05 & 0.081 & 0.036 & 0.53 \\
\hline $95 \% \mathrm{Cl}$ & $-4.68,0.42$ & $-1.23,1.98$ & $-0.82,2.91$ & & & \\
\hline Vitality & -1.52 & 2.73 & 3.86 & 0.003 & $<0.001$ & 0.28 \\
\hline $95 \% \mathrm{Cl}$ & $-4.06,1.01$ & I.13, 4.32 & $2.02,5.70$ & & & \\
\hline Social functioning & 1.43 & 4.72 & 4.72 & 0.060 & 0.074 & 0.996 \\
\hline $95 \% \mathrm{Cl}$ & $-1.65,4.52$ & $2.84,6.59$ & $2.54,6.91$ & & & \\
\hline Role-emotional & -0.75 & 3.25 & 4.00 & 0.037 & 0.018 & 0.59 \\
\hline $95 \% \mathrm{Cl}$ & $-4.13,2.64$ & $1.21,5.29$ & $1.62,6.37$ & & & \\
\hline Mental health & 0.33 & 3.17 & 5.10 & 0.082 & 0.006 & 0.11 \\
\hline $95 \% \mathrm{Cl}$ & $-2.55,3.22$ & I.37, 4.97 & $3.02,7.19$ & & & \\
\hline MCS & 2.56 & 4.48 & 5.85 & 0.25 & 0.059 & 0.25 \\
\hline $95 \% \mathrm{Cl}$ & $-0.38,5.50$ & $2.69,6.27$ & $3.76,7.94$ & & & \\
\hline PCS & -5.08 & 0.14 & -0.36 & $<0.001$ & $<0.001$ & 0.61 \\
\hline $95 \% \mathrm{Cl}$ & $-7.47,-2.70$ & $-1.32,1.61$ & $-2.08,1.36$ & & & \\
\hline
\end{tabular}

Note: The sample size in each MDI subgroup is slightly smaller than that in Table 2 due to the statistical model adjusting for MPR for which some patients had missing data.

Abbreviations: $\mathrm{Cl}$, confidence interval; MCS, mental component score; MDI, Movement Disorder Index; MPR, medication possession ratio; PCS, physical component score; SF-36, 36-Item Short Form Health Survey.

of their movement disorder severity level over the one-year study, as measured by the MDI, also had poorer clinical and functional outcomes and a higher rate of hospitalization compared with patients whose MDI scores either improved or remained the same.

Although current findings suggest that patients' sensitivity to develop antipsychotic-induced movement disorders is associated with a poor prognosis, the connection between EPS burden and poor clinical outcomes is not fully understood. It was previously proposed that this was driven by the burden of worsening EPS, such that the subjective discomfort of akathisia causes worsening of psychotic symptoms as a stressor and/or as a dysphoric cue. ${ }^{25}$ However, patients whose akathisia-related complaints responded to antiparkinsonian therapy did not show a better outcome on treatment with fluphenazine in that study. ${ }^{25}$ Likewise, the mild expression of neuroleptic-induced EPS was previously found to distinguish treatment-responsive patients from treatment-resistant patients. ${ }^{26}$

Notably, the three MDI subgroups were comparable on age, gender, and baseline psychiatric characteristics including diagnosis, comorbid diagnosis, and symptom severity. Due to the higher risk of EPS with first-generation antipsychotics than their second-generation counterparts, it is not surpris- ing that patients who received only first-generation antipsychotics in the previous year were more likely to be in the MDI-improved subgroup. It is worth noting that the MDIimproved subgroup had higher scores on both baseline MDI and antipsychotic adherence rate in the past year (ie, MPR). Prior research has shown that adherence with medication is associated with personality trait. ${ }^{27}$ It is possible that patients who adhered with their antipsychotic regimen prior to study enrollment were likely to be adherent during the study period. In addition, it is reasonable to expect patients with high baseline MDI scores to more likely be in the MDI-improved subgroup due to the regression toward the mean phenomenon. However, with the substantial changes of +1.2 in the MDIworsened subgroup and -1.5 in the MDI-improved subgroup, regression to the mean may not explain all the changes in MDI. Interaction between clinical outcome and EPS may be the major contributor to this observation.

Previous studies have suggested that a high burden of baseline EPS is associated with a poor response to treatment. ${ }^{28,29}$ The differences may be driven by the fact that our study captures EPS from all available EPS measures and parameters, including use of anticholinergic medications, which helps to suppress manifestation of EPS. There are also differences in methodology and study populations, ie, 
Case et $\mathrm{al}^{28}$ tried to predict outcome using baseline individual EPS, while we assessed the association between change in an EPS composite score with outcome. Rabinowitz et al ${ }^{29}$ linked premorbid level to change in maximum score on a single EPS measure in the treatment of patients experiencing a first episode of psychosis where the "stable-good" group had lower maximum Extrapyramidal Symptoms Rating Scale scores than the "stable-poor" group, but these differences were not statistically significant.

Moreover, our study suggests that even though patients had a high baseline EPS burden, resolving or reducing EPS (eg, MDI-improved) over the one-year study period was associated with better improvement in clinical and functional outcomes; conversely, if the baseline EPS burden was relatively low, worsening of MDI was associated with poor clinical and functional outcome. Furthermore, if the EPS burden at baseline was relatively low, no change in MDI score was associated with a better clinical and functional outcome. Although other studies have found that patients with more severe illness at baseline were more likely to develop EPS, ${ }^{30,31}$ the data suggest that astute clinicians recognize the presence or development of acute EPS as a signal to take appropriate steps to optimize antipsychotic therapy, possibly in order to avoid a poor clinical outcome.

The results of this pragmatic study would apply in realworld practice settings because it was designed to reflect usual care, by allowing physicians to adjust dosages and switch medications according to their discretion, including a heterogeneous patient population with various comorbid conditions such as substance abuse, and open-label administration of medication..$^{32,33}$

This study developed a simple index measure of EPS, ie, the MDI, which incorporates information from five well established measures of movement disorder. Thus, the MDI enables detection of EPS, even when captured by some but not all of the five component scores, facilitating more accurate interpretation of the EPS burden. Moreover, the MDI captures different aspects of movement disorders, reflecting a more complete clinical picture of this multifaceted phenomenon. In addition, the relationship between MDI profile and patients' clinical and functional outcomes suggests the potential utility of the MDI score. Moreover, the observation that the MDIworsened subgroup showed significant worsening on physical functional outcome (per SF-36 scales of bodily pain, role physical, physical functioning, and the PCS score) suggests the validity of the MDI, but this will require further research.

The MDI appears conceptually similar to the previously developed Movement Disorder Burden score. ${ }^{34}$ This effort, by Addington et al, ${ }^{34}$ combined the score of a movement disorder severity measure with use of adjunctive antiparkinsonian medications and duration of EPS burden into a Movement Disorder Burden score. However, instead of having one overall severity measure, most antipsychotic trials in schizophrenia include multiple measures of EPS. ${ }^{5,7}$ These multiple measures lack a consistent rating scale. In addition, the Movement Disorder Burden score was developed for and used in an eight-week study. ${ }^{34}$ In our naturalistic, pragmatic one-year study, some of the intervals between visits were long, the exact number of days of EPS was unknown, and our focus was on change in EPS profile over a one-year period, not on patients' aggregated mean index score for the one-year period.

The findings of this study need to be interpreted within the context of some limitations. First is the post hoc and exploratory nature of the analyses, pointing to the need for replication. Additional studies may help to clarify further the magnitude of impact that EPS has on functional and clinical outcomes. Second is the fact that the association between worsening on the MDI and poorer clinical and functional outcomes does not confirm causality. Treatment choice may be the cause of both the MDI profile and clinical outcome. However, due to the open-label, pragmatic design of the current study in which dosing adjustment and medication switching were allowed at the discretion of the attending physician, it is difficult to attribute the treatment effect to a specific drug, so we did not extend our MDI analysis to inference of treatment effect. Lastly, while this study assessed the time to all-cause study discontinuation and there was no statistically significant difference between the three MDI profile subgroups, the current analysis does not address the potential mediating effect of treatment adherence and treatment switches on clinical outcomes.

This study demonstrated that patients with schizophrenia who were treated with antipsychotics and experienced worsening of their movement disorder also experienced poorer clinical and functional outcomes. Recognition of the early onset of EPS or worsening of EPS should lead clinicians to optimize treatment for these potentially less responsive patients. This link between movement disorder profile and treatment outcomes deserves further study, along with replication of the findings with the promising new MDI.

\section{Disclosure}

All authors are employees of Eli Lilly and Company and/or one of its wholly owned subsidiaries. This study (F1D-USHGGD) was funded by Eli Lilly and Company. 


\section{References}

1. Weiden PJ. EPS profiles: the atypical antipsychotics are not all the same. J Psychiatr Pract. 2007;13:13-24.

2. Kane JM, Woerner M, Weinhold P, Wegner J, Kinon B, Borenstein M. Incidence of tardive dyskinesia: five-year data from a prospective study. Psychopharmacol Bull. 1984;20:387-389.

3. Glazer WM, Morgenstern H, Doucette JT. Predicting the long-term risk of tardive dyskinesia in outpatients maintained on neuroleptic medications. J Clin Psychiatry. 1993;54:133-139.

4. Jeste DV, Lacro JP, Palmer B, Rockwell E, Harris MJ, Caligiuri MP. Incidence of tardive dyskinesia in early stages of low-dose treatment with typical neuroleptics in older patients. Am J Psychiatry. 1999;156: 309-311.

5. Beasley CM Jr, Sanger T, Satterlee W, Tollefson G, Tran P, Hamilton S. Olanzapine versus placebo: results of a double-blind, fixed-dose olanzapine trial. Psychopharmacology. 1996;124:159-167.

6. Correll CU, Leucht S, Kane JM. Lower risk for tardive dyskinesia associated with second-generation antipsychotics: a systematic review of 1-year studies. Am J Psychiatry. 2004;161:414-425.

7. Lieberman JA, Stroup TS, McEvoy JP, et al. Effectiveness of antipsychotic drugs in patients with chronic schizophrenia. $N$ Engl J Med. 2005;353:1209-1223.

8. Miller DD, Caroff SN, Davis SM, et al. Extrapyramidal side-effects of antipsychotics in a randomised trial. Br J Psychiatry. 2008;193: 279-288.

9. Barnes TR. A rating scale for drug-induced akathisia. Br J Psychiatry. 1989;154:672-676.

10. Tollefson GD, Beasley CM Jr, Tran PV, et al. Olanzapine versus haloperidol in the treatment of schizophrenia and schizoaffective and schizophreniform disorders: results of an international collaborative trial. Am J Psychiatry. 1997;154:457-465.

11. Guy W. Abnormal involuntary movement scale (AIMS). In: ECDEU Assessment Manual for Psychopharmacology Revised. Rockville, MD: Alcohol, Drug Abuse, and Mental Health Administration, National Institute of Mental Health; 1976.

12. Simpson GM, Angus JW. A rating scale for extrapyramidal side effects. Acta Psychiatr Scand Suppl. 1970;212:11-19.

13. Tunis SL, Faries DE, Nyhuis AW, Kinon BJ, Ascher-Svanum H, Aquila R. Cost-effectiveness of olanzapine as first-line treatment for schizophrenia: results from a randomized, open-label, 1-year trial. Value Health. 2006;9:77-89.

14. American Psychiatric Association. Diagnostic and Statistical Manual of Mental Disorders, 4th ed. Washington, DC: American Psychiatric Association; 1994.

15. Kay SR, Fiszbein A, Opler LA. The positive and negative syndrome scale (PANSS) for schizophrenia. Schizophr Bull. 1987;13:261-276.

16. Davis JM, Chen N. The effects of olanzapine on the 5 dimensions of schizophrenia derived by factor analysis: combined results of the North American and international trials. J Clin Psychiatry. 2001;62:757-771.

17. Ware JE Jr, Sherbourne CD. The MOS 36-item short-form health survey (SF-36). I. Conceptual framework and item selection. Med Care. 1992;30:473-483.

18. Ware JE Jr, Kosinski M, Bayliss MS, McHorney CA, Rogers WH, Raczek A. Comparison of methods for the scoring and statistical analysis of SF-36 Health Profile and Summary Measures: summary of results from the Medical Outcomes Study. Med Care. 1995; 33 S4 Suppl:AS264-AS279.

Neuropsychiatric Disease and Treatment

\section{Publish your work in this journal}

Neuropsychiatric Disease and Treatment is an international, peerreviewed journal of clinical therapeutics and pharmacology focusing on concise rapid reporting of clinical or pre-clinical studies on a range of neuropsychiatric and neurological disorders. This journal is indexed on PubMed Central, the 'PsycINFO' database and CAS.
19. Carlson CD, Cavazzoni PA, Berg PH, Wei H, Beasley CM, Kane JM. An integrated analysis of acute treatment-emergent extrapyramidal syndrome in patients with schizophrenia during olanzapine clinical trials: comparisons with placebo, haloperidol, risperidone, or clozapine. J Clin Psychiatry. 2003;64:898-906.

20. Schooler NR, Kane JM. Research diagnosis for tardive dyskinesia. Arch Gen Psychiatry. 1982;39:486-487.

21. Kinon BJ, StaufferVL, Kollack-Walker S, Chen L, Sniadecki J. Olanzapine versus aripiprazole for the treatment of agitation in acutely ill patients with schizophrenia. J Clin Psychopharmacol. 2008;28:601-607.

22. Meltzer HY, Cucchiaro J, Silva R, et al. Lurasidone in the treatment of schizophrenia: a randomized, double-blind, placebo- and olanzapinecontrolled study. Am J Psychiatry. 2011;168:957-967.

23. Kinon BJ, Kollack-Walker S, Stauffer V, Liu-Seifert H. Reduction in tardive dyskinesia symptoms during treatment with olanzapine or haloperidol. J Clin Psychopharmacol. 2012;32:420-422.

24. Kinon BJ, Kane JM, Chakos M, Munne R. Possible predictors of neuroleptic-resistant schizophrenic relapse: influence of negative symptoms and acute extrapyramidal side effects. Psychopharmacol Bull. 1993;29:365-369.

25. Levinson DF, Simpson GM, Singh H, et al. Fluphenazine dose, clinical response, and extrapyramidal symptoms during acute treatment. Arch Gen Psychiatry. 1990;47:761-768.

26. Kinon BJ, Kane JM, Johns C, et al. Treatment of neuroleptic-resistant schizophrenic relapse. Psychopharmacol Bull. 1993;29:309-314.

27. Emilsson M, Berndtsson I, Lotvall J, et al. The influence of personality traits and beliefs about medicines on adherence to asthma treatment. Prim Care Respir. 2011;20:141-147.

28. Case M, Stauffer VL, Ascher-Svanum H, et al. The heterogeneity of antipsychotic response in the treatment of schizophrenia. Psychol Med. 2011;41:1291-1300.

29. Rabinowitz J, Harvey PD, Eerdekens M, Davidson M. Premorbid functioning and treatment response in recent-onset schizophrenia. $\mathrm{Br}$ J Psychiatry. 2006;189:31-35.

30. Chakos MH, Mayerhoff DI, Loebel AD, et al. Incidence and correlates of acute extrapyramidal symptoms in first episode of schizophrenia. Psychopharmacol Bull. 1992;28:81-86.

31. Aguilar EJ, Keshavan MS, Martinez-Quiles MD, et al. Predictors of acute dystonia in first-episode psychotic patients. Am J Psychiatry. 1994;151:1819-1821.

32. Freemantle N, Drummond M. Should clinical trials with concurrent economic analyses be blinded? JAMA. 1997;277:63-64.

33. Tunis SL, Johnstone BM, Kinon BJ, Barber BL, Browne RA. Designing naturalistic prospective studies of economic and effectiveness outcomes associated with novel antipsychotic therapies. Value Health. 2000;3:232-242.

34. Addington DE, Pantelis C, Dineen M, Benattia I, Romano SJ. Efficacy and tolerability of ziprasidone versus risperidone in patients with acute exacerbation of schizophrenia or schizoaffective disorder: an 8-week, double-blind, multicenter trial. J Clin Psychiatry. 2004;65: 1624-1633.

\section{Dovepress}

The manuscript management system is completely online and includes a very quick and fair peer-review system, which is all easy to use. Visit $\mathrm{http}: / / \mathrm{www}$.dovepress.com/testimonials.php to read real quotes from published authors. 